\title{
Transcriptome analysis of a thermophilic and hydrogenogenic carboxydotroph Carboxydothermus pertinax
}

\author{
Yuto Fukuyama $^{1} \cdot$ Kimiho Omae $^{1} \cdot$ Takashi Yoshida $^{1} \cdot$ Yoshihiko Sako $^{1}$
}

Received: 9 January 2019 / Accepted: 21 March 2019 / Published online: 3 April 2019

(c) The Author(s) 2019

\begin{abstract}
A thermophilic and hydrogenogenic carboxydotroph, Carboxydothermus pertinax, performs hydrogenogenic CO metabolism in which CODH-II couples with distally encoded ECH. To enhance our knowledge of its hydrogenogenic CO metabolism, we performed whole transcriptome analysis of C. pertinax grown under $100 \% \mathrm{CO}$ or $100 \% \mathrm{~N}_{2}$ using RNA sequencing. Of the 2577 genes, 36 and 64 genes were differentially expressed genes (DEGs) with false discovery rate adjusted $P$ value $<0.05$ when grown under $100 \% \mathrm{CO}$ or $100 \% \mathrm{~N}_{2}$, respectively. Most of the DEGs were components of 23 gene clusters, suggesting switch between metabolisms via intensive expression changes in a relatively low number of gene clusters. Of the 9 significantly expressed gene clusters under $100 \% \mathrm{CO}, \mathrm{CODH}-\mathrm{II}$ and ECH gene clusters were found. Only the ECH gene cluster was regulated by the $\mathrm{CO}$-responsive transcriptional factor $\mathrm{CooA}$, suggesting that others were separately regulated in the same transcriptional cascade as the $\mathrm{ECH}$ gene cluster. Of the 14 significantly expressed gene clusters under $100 \% \mathrm{~N}_{2}$, ferrous iron transport gene cluster involved in anaerobic respiration and prophage region were found. Considering that the expression of the temperate phage was strictly repressed under $100 \% \mathrm{CO}$, hydrogenogenic CO metabolism might be stable for C. pertinax.
\end{abstract}

Keywords Hydrogenogenic carboxydotroph $\cdot$ Carbon monoxide dehydrogenase $\cdot$ RNA sequencing $\cdot$ Carboxydothermus pertinax

\section{Abbreviations \\ CODH Carbon monoxide dehydrogenase \\ ECH Energy-converting hydrogenase \\ DEG Differential expression gene \\ LTTR LysR-type transcriptional regulator}

\section{Introduction}

Carbon monoxide (CO) is toxic for many organisms. However, some prokaryotes, called CO-utilizing microbes (carboxydotrophs), can use $\mathrm{CO}$ as the source of energy and carbon for their growth (CO metabolism) (Mörsdorf et al.

Communicated by A. Driessen.

Electronic supplementary material The online version of this article (https://doi.org/10.1007/s00792-019-01091-x) contains supplementary material, which is available to authorized users.

Yoshihiko Sako

sako@kais.kyoto-u.ac.jp

1 Division of Applied Biosciences, Graduate School of Agriculture, Kyoto University, Kyoto 606-8502, Japan
1992). Owing to the low redox potential $(-520 \mathrm{mV})$ of CO (Grahame and DeMoll 1995), anaerobic carboxydotrophs can couple $\mathrm{CO}$ oxidation to various reduction reactions such as sulfate to sulfide (sulfate-reducers), water to $\mathrm{H}_{2}$ (hydrogenogens), $\mathrm{Fe}^{3+}$ to $\mathrm{Fe}^{2+}$ ( $\mathrm{Fe}[\mathrm{III}]$-reducers), and $\mathrm{CO}_{2}$ to acetate (acetogens) or methane (methanogens) (Oelgeschläger and Rother 2008; Sokolova et al. 2009). Many anaerobic and thermophilic carboxydotrophs have been isolated (Sokolova et al. 2009) from hydrothermal environments where CO is supplied by volcanic gas, photochemical and thermochemical decomposition of organic matter, and as a by-product of certain thermophiles (King and Weber 2007; Techtmann et al. 2009). Among them, 25 strains representing 13 genera (21 species) have been reported as hydrogenogenic carboxydotrophs (Sokolova and Lebedinsky 2013). Recently, in addition to these 25 strains, three thermophilic and hydrogenogenic carboxydotrophs, namely Thermococcus barophilus (Kozhevnikova et al. 2016), Thermoanaerobacter kivui (Weghoff and Müller 2016), and Parageobacillus thermoglucosidasius (Mohr et al. 2018), have been reported. Although a number of strains of Moorella thermoacetica have been isolated, only one strain (M. thermoacetica strain AMP) exhibits hydrogenogenic carboxydotrophy, whereas 
the other strains are acetogenic carboxydotrophs (Jiang et al. 2009). Because of their ability to use potentially toxic CO and produce $\mathrm{H}_{2}$ as the source of energy for other microbes, hydrogenogenic carboxydotrophs are assumed to be important 'CO scavengers' and primary producers in the environment (Sokolova and Lebedinsky 2013; Techtmann et al. 2009; Yoneda et al. 2013, 2015).

In anaerobic carboxydotrophs, $\mathrm{CODH}$, with $\mathrm{Ni}$ in its active center, catalyzes the oxidoreductive interconversion between $\mathrm{CO}$ and $\mathrm{CO}_{2}$ (Ragsdale 2004). The function of $\mathrm{CODH}$ has been principally predicted by the genomic context of each CODH gene (cooS; Techtmann et al. 2012). A model of hydrogenogenic carboxydotrophs, Carboxydothermus hydrogenoformans, possesses five genes (cooS-I to $-V$ ) which code for the catalytic subunits of CODHs (CODHI-V) on its genome (Wu et al. 2005). Based on the genomic context of the gene clusters including each $\operatorname{coos}$ and/or empirical evidence, their functions are predicted as follows: CODH-I, energy conversion conjugated with $\mathrm{ECH}$; CODHII, NAD $(\mathrm{P}) \mathrm{H}$ generation; CODH-III, carbon fixation in the Wood-Ljungdahl pathway conjugated with acetyl-CoA synthase (ACS); and CODH-IV, oxidative stress response (Wu et al. 2005; Svetlitchnyi et al. 2001). CODH-V does not conserve sequences responsible for its active center, and hence, its physiological function remains unknown (Inoue et al. 2013). cooS-I is arranged in a gene cluster with genes coding for an electron transfer protein (CooF) (Kerby et al. 1992), $\mathrm{Ni}$ insertion protein (CooC) (Kerby et al. 1997), a transcriptional factor (CooA) (Shelver et al. 1995), and ECH-related genes. In most hydrogenogenic carboxydotrophs, cooS-I and $\mathrm{ECH}-$ related genes form a gene cluster (CODH-ECH gene cluster) or are closely arranged (Sokolova et al. 2009). The hydrogenogenic $\mathrm{CO}$ utilization is performed by a complex of three enzymes; CODH-I, CooF, and ECH complex. CO is oxidized by CODH-I and the generated electron is transferred to CooF. Subsequently, this electron is coupled to proton reduction via the ECH complex, producing $\mathrm{H}_{2}$ and forming a proton gradient (Svetlitchnyi et al. 2001; Soboh et al. 2002).

Transcription of the genes in the CODH gene cluster in hydrogenogenic $\mathrm{CO}$ metabolism is activated by $\mathrm{CO}$ responsive transcriptional factors CooA, RcoM (Kerby et al. 2008), and CorQR (Kim et al. 2015). Of these, CooA is well characterized in the hydrogenogenic carboxydotroph, Rhodospirillum rubrum (Aono et al. 1996; Roberts et al. 2004) and is present in most of the hydrogenogenic carboxydotrophs (Youn et al. 2004). CooA belongs to the cyclic AMP receptor protein family (Shelver et al. 1995). Homodimeric heme protein CooA is inactive in the absence of $\mathrm{CO}$ (Shelver et al. 1997). When CooA senses CO, ligand replacement in CooA leads to its conformational change making it active (Shelver et al. 1997). The active form of CooA can bind to the promoter region, thereby activating transcription through contact with RNA polymerase (Leduc et al. 2001). In the $R$. rubrum genome, CODH gene cluster and $\mathrm{ECH}$ gene cluster are closely arranged and the CooA-binding site is found upstream of both $c o o F$ in the $\mathrm{CODH}$ gene cluster and cooM in the ECH gene cluster (Fox et al. 1996; Rajeev et al. 2012). The previous study shows that CooA homologs are divided into two phylogenetically distinct groups (CooA-1 and CooA-2). CooA-1 is found in the majority of CooA possessing carboxydotrophs, whereas CooA-2 is found in some carboxydotrophs that possess multiple CODH gene clusters in their genomes (Techtmann et al. 2011). Furthermore, CObinding assay of two CooA groups shows that both CooA-1 and CooA-2 are in their active forms in high $\mathrm{CO}$ concentration, whereas only CooA- 2 is in active form even in low $\mathrm{CO}$ concentration (Techtmann et al. 2011). This difference in CO activation in the two CooA groups enables the bacterium to regulate multiple $\mathrm{CODH}$ gene clusters across wide range of CO concentrations (Techtmann et al. 2011). In addition to CooA, recent studies have reported other anaerobic COresponsive transcriptional factors $\mathrm{RcoM}$ and $\mathrm{CO}$-responsive regulatory system CorQR. Similar to CooA, RcoM, whose gene is adjacent to CODH and ECH gene clusters in the hydrogenogenic carboxydotroph Rubrivivax gelatinosus (phylum Proteobacteria) (Wawrousek et al. 2014), possesses a potential CO-sensor domain-containing heme (Kerby et al. 2008). CorQR pair is composed of CorQ with a DNA-binding domain of LysR-type transcriptional regulator (LTTR) family and CorR with 4-vinyl reductase domain instead of heme to sense CO (Kim et al. 2015). Genes encoding CorQR pair also flanked with CODH-ECH gene cluster in the hydrogenogenic carboxydotrophic archaeon, Thermococcus onnurineus (phylum Euryarchaeota) (Kim et al. 2015).

To date, only a few transcriptional studies about hydrogenogenic $\mathrm{CO}$ metabolism have been reported. A transcriptomic analysis of the sulfate-reducing carboxydotroph Desulfovibrio vulgaris using microarray reports that the expression of $\operatorname{cooS}$ is dependent on active CooA under low CO concentration (Rajeev et al. 2012). In addition, genome-wide primary transcriptomic analysis of T. onnurineus reports that the expression of $\operatorname{cooS}$ is significantly upregulated when they utilize $\mathrm{CO}$ as the source of energy for $\mathrm{H}_{2}$ production (Cho et al. 2017). However, there are limited data on comprehensive gene expression pattern of hydrogenogenic $\mathrm{CO}$ metabolism.

Carboxydothermus pertinax is isolated from an acidic hot spring in Japan (Yoneda et al. 2012). Despite of its hydrogenogenic carboxydotrophy (Yoneda et al. 2012), as per genome analysis, $C$. pertinax lacks genes encoding CODHI catalytic subunit (CooS-I) and its transcriptional factor CooA-1 in their CODH-I-ECH gene cluster (Fukuyama et al. 2017). Furthermore, gene expression analysis in $C$. pertinax has shown that genes encoding CODH-II catalytic subunit (cooS-II) and distantly encoding the ECH catalytic 
large and small subunits are remarkably upregulated under $100 \%$ CO, suggesting that $C$. pertinax performs hydrogenogenic $\mathrm{CO}$ metabolism in which CODH-II couples with distal ECH (Fukuyama et al. 2018). Since $C$. pertinax possesses one CooA homolog (CooA-2) unlike $C$. hydrogenoformans possessing two CooA homologs, its transcriptional regulation from $\mathrm{CO}$ response is expected to be simpler than that of $C$. hydrogenoformans. Therefore, study of $C$. pertinax will further help us to understand the regulation mechanism of hydrogenogenic $\mathrm{CO}$ metabolism. In this study, we performed the whole transcriptome analysis of $C$. pertinax grown on pyruvate under $100 \% \mathrm{CO}$ or $100 \% \mathrm{~N}_{2}$ by RNA sequencing (RNA-Seq).

\section{Materials and methods}

\section{Growth conditions for transcriptome analysis}

To prepare RNA for transcriptome analysis, C. pertinax was grown at $65{ }^{\circ} \mathrm{C}$ in modified DSM medium 507 under a headspace of $100 \% \mathrm{CO}$ or $100 \% \mathrm{~N}_{2}$ gas according to methods previously described (Fukuyama et al. 2018). We added sodium thiosulfate (final concentration, $1 \mathrm{~g} / \mathrm{L}$ ) as the terminal electron acceptor and sodium pyruvate (final concentration, $2 \mathrm{~g} / \mathrm{L}$ ) as the electron donor and carbon source to the medium in both the gas phase conditions to collect enough cells for analysis. Growth was assessed by direct enumeration of SYBR gold-stained cells collected on $0.2 \mu \mathrm{m}$ black polycarbonate membrane filters (Advantec, Tokyo, Japan) using a fluorescent microscope (Olympus, Tokyo, Japan). The cells exponentially grown in pre-culture were inoculated to fresh medium and cultivated routinely.

\section{Transcriptome analysis of $C$. pertinax}

When $C$. pertinax reached the late exponential phase as indicated by arrows (Fig. S1), $10 \mathrm{~mL}$ of the culture in both the conditions was collected and total RNA was extracted according to the methods previously described (Fukuyama et al. 2018). After removal of contaminating DNA using TURBO DNase (Invitrogen, Carlsbad, CA, USA), total RNA was purified using Agencourt RNAClean XP (Beckman Coulter, Brea, CA, USA) according to the manufacturer's instructions. Quantification was performed in the Agilent 2100 Bioanalyzer with Agilent RNA6000 pico kit (Agilent Technologies, Santa Clara, CA, USA). Ribosomal RNA (rRNA) was depleted from the purified total RNA using Ribo-Zero ${ }^{\mathrm{TM}}$ Magnetic Kit (Bacteria) (Epicentre, Madison, WI, USA) according to the manufacturer's instructions. After rRNA removal, the purified total RNA, which was extracted from total $60 \mathrm{~mL}$ from the two replicates, was merged to obtain sufficient total RNA for RNA-Seq. Then, the merged total RNA was reverse transcribed to obtain double-strand cDNA (ds cDNA) using PrimeScript DoubleStrand cDNA Synthesis Kit (TaKaRa Bio, Shiga, Japan) for RNA-Seq. The ds cDNA library was constructed with $75 \mathrm{bp}$ paired-end libraries prepared by Nextera ${ }^{\circledR}$ XT DNA sample prep kit (Illumina, San Diego, CA, USA) and sequenced using Illumina MiSeq system (Illumina). For reverse transcription quantitative PCR (RT-qPCR), the purified total RNA was reverse transcribed to single-strand cDNA (ss cDNA) using SuperScript III First-Strand Synthesis System (Invitrogen).

\section{RNA-Seq data analysis}

Generated high-quality reads of $C$. pertinax with Q30 (sequence error rate lower than $0.1 \%$ ) mapped to their draft genome (BDJK01000000) using Tophat version 2.0.13 (Trapnell et al. 2009) with Bowtie2 version 2.2.2 (mismatches $\leq 2$ bp) (Langmead and Salzberg 2012). We manually removed contaminated rRNA reads which showed high similarity to $C$. pertinax $5 \mathrm{~S}, 16 \mathrm{~S}$, and $23 \mathrm{~S}$ rRNA. Read count per gene under both conditions was estimated using featureCounts (Liao et al. 2014). Rarefaction curves for reads under both conditions were constructed using PAST ver.3.17 (Hammer et al. 2001). Gene expression levels were compared and normalized using the $\mathrm{R}$ statistical package edgeR (Robinson et al. 2010). DEGs were identified as significantly expressed under $100 \% \mathrm{CO}$ or $100 \% \mathrm{~N}_{2}$ when their $\log 2$ fold change was $>1$ or $<-1$, respectively, and their FDR adjusted $P$ value ( $Q$ value) was $<0.05$.

\section{Analysis to predict the function of DEGs}

As a unit of polycistronic transcription, a gene cluster was predicted based on the following criteria: (1) intergenic distance between genes was less than $300 \mathrm{bp}$, (2) genes were encoded in the same strand, and (3) the visual pattern of read alignment to a locus on $C$. pertinax genome. The Integrative Genomics Viewer (IGV) software was used to visualize the patterns of read alignment (Thorvaldsdottir et al. 2013). To predict the functions of DEGs, these protein sequences were annotated using BLASTp search (Altschul et al. 1990, 1997) with an e value of $1 \mathrm{e}^{-5}$ at an effective database size of $10^{7}$ against the COG database (Tatusov 2000). The upstream regions (300 bp) of the predicted gene cluster containing DEGs and solely transcribed DEGs were collected from the C. pertinax draft genome. The primary sigma factor recognition sequences were predicted using Bacterial Promoter Prediction Program (BPROM) with default parameters (Solovyev and Salamov 2011).

The promoter sequences were aligned separately for each motif ( -10 motif and -35 motif). Logos were prepared using weblogo for visualization (Crooks et al. 2004). To 
discover motifs in the upstream regions, we used MEME ver5.0.2 program with default parameters (Bailey and Elkan 1994).

Prophage regions encoded in contigs (cut-off $<1500 \mathrm{bp}$ ) from the genomes of the three Carboxydothermus species except for the already analyzed $C$. hydrogenoformans $(\mathrm{Wu}$ et al. 2005) were predicted using PHAge Search ToolEnhanced Release (PHASTER) (Arndt et al. 2016). To classify the predicted prophages in three Carboxydothermus species based on genome-wide similarities, a viral proteomic tree was generated by ViPTree (Nishimura et al. 2017b). The all-against-all distance matrix between viral reference genomes and the predicted phages was calculated on the basis of the normalized bit score of tBLASTx $\left(S_{G}\right)$ (Nishimura et al. 2017a), and the proteomic tree was built with BIONJ using the distance matrix in the ViPTree.

\section{RT-qPCR validation for the expression of CO metabolism-related genes}

To validate the RNA-Seq expression data, 10 predicted CO metabolism-related genes were selected for RT-qPCR. RTqPCR primers have been described in the previous study (Fukuyama et al. 2018). PCR amplification was performed according to the previous study (Fukuyama et al. 2018). We served same cDNA samples as RNA-Seq to RT-qPCR. The detection limit of the transcript levels of mRNA for target genes was $1.00 \times 10^{2}$ copies $/ \mu \mathrm{L}$. Relative transcript amounts were calculated using $r r s D$ (16S rRNA) transcripts as an internal standard. All RT-qPCR data represent the mean value of at least triplicate biological determinations.

\section{Accession number of the sequence}

RNA-Seq data have been submitted to the DNA Data Bank of Japan Sequence Read Archive under the accession no. DRA007734.

\section{Results}

\section{Overview of RNA-Seq}

Carboxydothermus pertinax grew under both $100 \% \mathrm{CO}$ and $100 \% \mathrm{~N}_{2}$ conditions (Fig. S1). Under $100 \% \mathrm{CO}$ (carboxydotrophic growth), doubling time was $2.3 \mathrm{~h}$ with a final cell density of $8.25 \times 10^{7} \pm 1.05 \times 10^{7}$ cells $/ \mathrm{mL}$. Under $100 \% \mathrm{~N}_{2}$ (heterotrophic growth), and doubling time was $1.9 \mathrm{~h}$ with a final cell density of $4.07 \times 10^{8} \pm 1.68 \times 10^{7}$ cells $/ \mathrm{mL}$. Total RNA was extracted from cells at late exponential phase in both conditions and subjected to RNA-Seq (Fig. S1). A total of approximately $3.54 \mathrm{M}$ and $3.74 \mathrm{M}$ high-quality reads were obtained from $100 \% \mathrm{CO}$ and $100 \% \mathrm{~N}_{2}$ conditions, respectively. The total number of the mapped reads to the $C$. pertinax draft genome was $2.28 \mathrm{M}$ and $1.95 \mathrm{M}$ with $100 \%$ $\mathrm{CO}$ and $100 \% \mathrm{~N}_{2}$, respectively (Table S1). Rarefaction curves of the mapped reads under both conditions showed that sequencing data from each condition was exhaustive to describe the transcriptional profile when read counts reached approximately $1.0 \mathrm{M}$ (Fig. S2), suggesting that the count of mapped genes was sufficient for RNA-Seq analysis under both conditions.

In general, central component of bacterial transcription is multi-subunit-DNA-dependent RNA polymerase. When we searched for sigma factors in C. pertinax, 13 sigma factors (one primary sigma factor, 11 alternative sigma factors as sigma ${ }^{70}$ family, and one sigma ${ }^{54}$ ) were found (Table S2). Read count of the primary sigma factor was 6495 and 2855 under $100 \% \mathrm{CO}$ and $100 \% \mathrm{~N}_{2}$, respectively. These read counts were an order of magnitude higher among the other sigma $^{70}$ factors including sigma ${ }^{70}$ factors for sporulation under both conditions (Table S2). These results clearly indicated that the obtained RNA-Seq reads reflected expression patterns of exponentially growing cells.

Under $100 \% \mathrm{CO}$ or $100 \% \mathrm{~N}_{2}$ conditions, 36 genes and 64 genes were identified as DEGs $(Q$ value $<0.05)$, respectively (Fig. 1). A ratio of the 2577 genes in $C$. pertinax draft genome to the DEGs was no more than $1.4 \%$ under $100 \%$ $\mathrm{CO}$ and $2.5 \%$ under $100 \% \mathrm{~N}_{2}$ conditions, respectively. Seventy-four percent of the DEGs under 100\% CO and $91 \%$ of the DEGs under $100 \% \mathrm{~N}_{2}$ were components of 9 and 14 gene clusters, respectively (Table 1 ). The remaining 8 DEGs under $100 \%$ CO and 6 DEGs under $100 \% \mathrm{~N}_{2}$ were solely transcribed. As significantly expressed gene clusters are

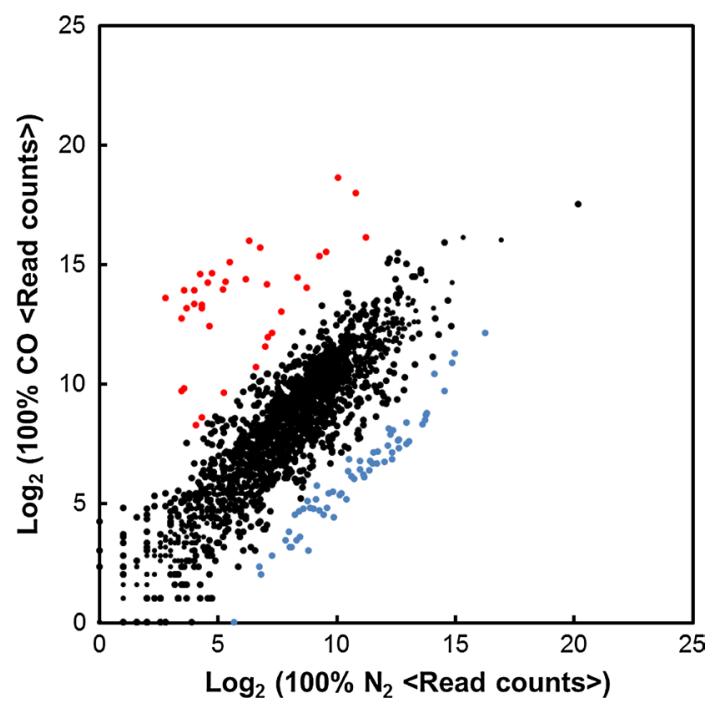

Fig. 1 Comparison of read counts between C. pertinax grown under $100 \% \mathrm{CO}$ and $100 \% \mathrm{~N}_{2}$. Each plot shows an open-reading frame. Red plots, upregulated DEGs; blue plot, downregulated DEGs; black, unchanged genes 


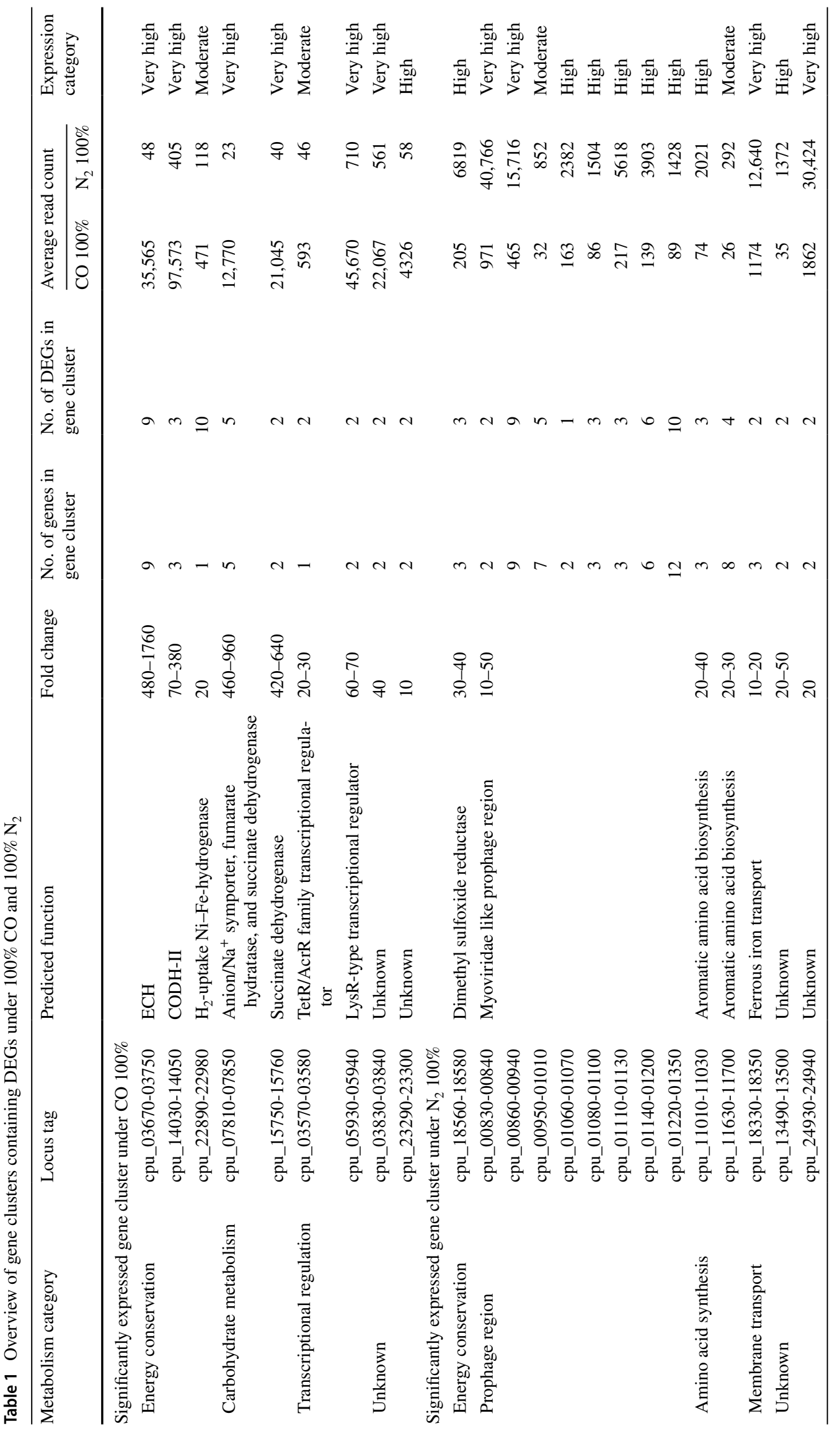


expected to play key roles in both the conditions, we classified them into three categories based on average read counts per kilobase of the genes in the gene clusters containing DEGs (Table 1): very high (average read counts $\geq 10,000$ ), high (average read counts $\geq 1000$ ), and moderate (average read counts $\geq 100$ ).

\section{Significantly expressed gene clusters under $100 \%$ CO or $100 \% \mathrm{~N}_{2}$}

Of the 6 gene clusters in the 'very high' category under $100 \%$ CO (Table 1), the two gene clusters (cpu_1403014050 and cpu_03670-03750; 70-380 and 480-1760 fold changes, respectively) were related to energy conservation and encoded CODH-II and ECH, which are essential proteins for hydrogenogenic CO metabolism (Fukuyama et al. 2018) (Fig. 2; Table S3). Furthermore, the two gene clusters were related to carbohydrate metabolism (460-960 and 420-640 fold changes, respectively; Table S3). Of these, the gene cluster (cpu_07810-07850) composed of five genes encoding divalent anion/ $/ \mathrm{Na}^{+}$symporter, fumarate hydratase $\alpha$ and $\beta$ subunits, succinate dehydrogenase flavoprotein, and iron-sulfur subunit. The other gene cluster (cpu_1575015760) composed of two genes encoding succinate dehydrogenase iron-sulfur and cytochrome b subunit. These gene products catalyze the oxidoreductive reaction between succinate and malate in tricarboxylic acid (TCA) cycle. The gene cluster (cpu_05930-05940; 60-70 fold changes) was composed of two genes encoding LTTR, involved in transcriptional regulation, and a hypothetical protein. In addition, a gene encoding another LTTR (cpu_07800) was also identified as a sole DEG (220 fold change). The function of the rest of the gene cluster (cpu_03830-03840) was not predicted from their gene products. Consequently, products of these six gene clusters were considered to play an important and specific role in their hydrogenogenic CO metabolism.

Next, we annotated three other categories (high or moderate; Table 1 and S3). These three gene clusters were composed of the following genes: two hypothetical genes (cpu_23290-23300; high), $10 \mathrm{H}_{2}$-uptake Ni-Fe-hydrogenase genes (cpu_22890-22980; moderate), and TetR/AcrR family transcriptional regulator gene and sodium/phosphate symporter (cpu_03570-03580; moderate).

Of the four gene clusters in the 'very high' category under $100 \% \mathrm{~N}_{2}$ (Table 1 and S4), the two gene clusters (cpu_00830-00840 and cpu_00860-00940; 40 and 30-50 fold changes, respectively) were a part of the prophage region in C. pertinax (Table S4). From the viral proteomic tree generated using ViPTree, this prophage region (54 genes) was close to P2-like Myoviridae viruses, Vibrio virus X29 (NC_024369), and Vibrio phage phi 2 (KJ545483) (Fig. S4). The gene cluster (cpu_18330-18350; 10-20 fold change) was composed of two genes encoding ferrous iron transport proteins A and B (Lau et al. 2016). In addition,
Fig. 2 Transcriptomic read mapping pattern of the CODHII gene cluster (a) and the ECH gene cluster (b). Part of genome-wide overview of reads mapped to the $C$. pertinax draft genome at samples in the CODH-II gene cluster (a) and the ECH gene cluster (b). Read abundance was displayed in a logarithmic scale of $1-30,000$ by Integrative Genomics Viewer (Thorvaldsdottir et al. 2013). Red box, DEG under 100\% CO; White box, not DEG under $100 \%$ CO. Positions of predicted sigma ${ }^{70}$ promoter sequence was predicted using BPROM with high linear discrimination function score (> 5; Solovyev and Salamov 2011). Black arrows, the position of predicted sigma ${ }^{70}$ promoter sequence. Red arrow, the position of predicted sigma ${ }^{70}$ promoter sequence with already known CooA-binding site
(A) $\mathrm{CODH}-$ Il gene cluster (cpu_14030-14050)

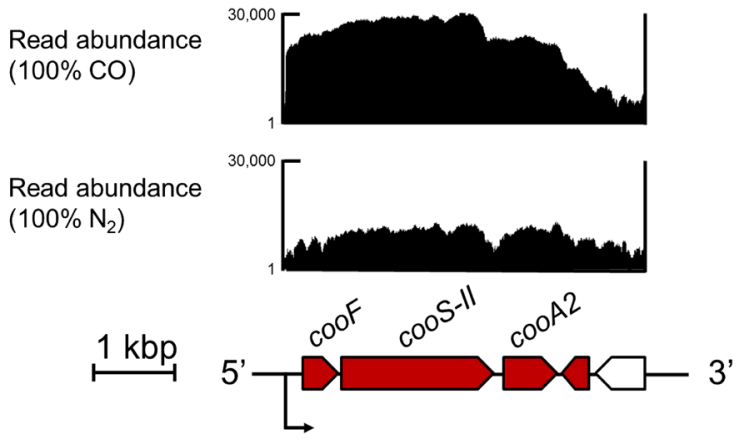

(B) $\mathrm{ECH}$ gene cluster (cpu_03670-03750)

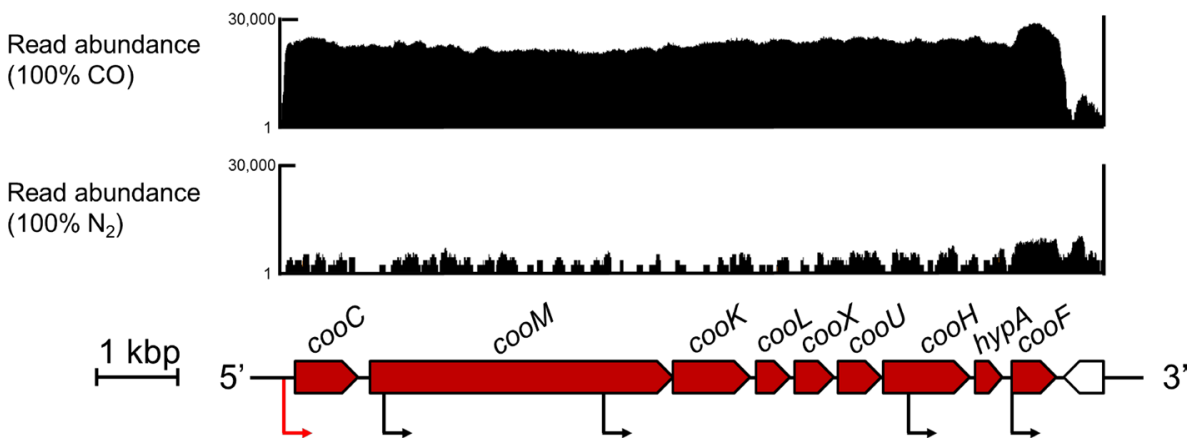


a gene (cpu_17460) encoding ferrous iron permease was identified as sole DEG (10 fold change). The function of the rest of the gene cluster (cpu_24930-24940) could not be predicted from their gene products. Products of these four gene products were also considered to play an important role in their heterotrophic growth.

Of the 10 gene clusters in high or moderate categories under $100 \% \mathrm{~N}_{2}$ (Table 1 and S4), the gene cluster (cpu_1856018580; high) was involved in energy conservation and encoded dimethyl sulfoxide reductase catalytic molybdopterin subunit, iron-sulfur cluster protein, and integral membrane protein. The six gene clusters (cpu_01060-01070, cpu_01080-01100, cpu_01110-01130, cpu_01140-01200, and cpu_01220-01350; high, cpu_00950-01010; moderate) were found in the prophage region. Furthermore, the two gene clusters (cpu_11010-11030, high; cpu_11630-11700, moderate) were involved in aromatic amino acid biosynthesis. The function of the rest of the gene cluster (cpu_13490-13500; high) could not be predicted from their gene products.

\section{Expressions of genes involved in hydrogenogenic CO metabolism}

Apart from the largely upregulated CODH-II gene cluster, RNA-Seq showed no significant expression changes of the $\mathrm{CODH}$ (CODH-III-V). In addition to ECH, C. pertinax possesses the $\mathrm{H}_{2}$-uptake $\mathrm{Ni}$-Fe-hydrogenase gene cluster. In this gene cluster, read count of all genes were relatively low in both the conditions and only one gene (cpu_22950) encoding maturation factor for $\mathrm{H}_{2}$-uptake $\mathrm{Ni}$-Fe-hydrogenase was identified as DEG.

To validate RNA-Seq, we performed gene expression analysis for 10 genes (coos-IIA2F1 in CODH-II gene cluster, cooS-III-V in CODH-III-V gene cluster, cooLH in ECH gene cluster, and hyaAB in $\mathrm{H}_{2}$-uptake $\mathrm{Ni}-\mathrm{Fe}$-hydrogenase gene cluster) using RT-qPCR (Fig. S4). The relative transcript levels of five genes (cooS-II, CooA2, $\mathrm{cooF} 1, \mathrm{cooH}$, and $\mathrm{cooL}$ ) under $100 \%$ CO were 20-640-fold higher than those under $100 \%$ $\mathrm{N}_{2}$ (Fig. S4). Relative transcript levels of the three remaining genes (cooS-III-V) were not changed. Of them, relative transcript levels of $c o o S-I V$ were below the limit of detection $\left(1.00 \times 10^{2}\right.$ copies $\left./ \mu \mathrm{L}\right)$. Furthermore, relative transcript levels of the two genes (hyaA and hyaB) were relatively higher under $100 \%$ CO. Consequently, RT-qPCR analysis for these genes supported the RNA-Seq data (Fig. S4).

\section{Analysis of the regulation mechanism under hydrogenogenic CO metabolism}

To predict the regulation mechanism under hydrogenogenic CO metabolism, we explored the transcription start site (TSS) from $300 \mathrm{bp}$ upstream of 36 transcriptional regions (23 gene clusters containing DEGs and 13 sole DEGs), except for two transcriptional regions, which were significantly transcribed by the polar effect of their upstream. We assigned 36 TSSs from all promoter regions, regardless of their transcriptional categories (very high, high, and moderate). These 5'-untranslated region lengths of transcripts were ranged from 19 to $239 \mathrm{bp}$. The -35 motif and -10 motif (Wösten 1998) for primary sigma factor were strictly conserved among all the promoter regions in both the conditions (Fig. S5).

Among the 16 promoter regions of the significantly expressed transcriptional regions under $100 \% \mathrm{CO}$, the CooA-binding site was conserved only in the ECH gene cluster. Expect for the ECH gene cluster, we searched conserved binding motifs for transcriptional factor among other promoter regions. However, there is no consensus motif with a significantly low $E$ value in the three transcriptional categories. Among the 20 promoter regions of the significantly expressed transcriptional regions under $100 \% \mathrm{~N}_{2}$, there is no consensus motif with a significantly low $E$ value in three transcriptional categories.

\section{Discussion}

In this study, we performed the whole transcriptome analysis of $C$. pertinax possessing only one CO-responsive transcriptional factor (CooA-2) as the first RNA-Seq report in hydrogenogenic carboxydotrophic bacterium. Total RNA from C. pertinax cells which grew under $100 \%$ CO and $100 \% \mathrm{~N}_{2}$ were compared to understand the regulation mechanism between hydrogenogenic $\mathrm{CO}$ metabolism and heterotrophic metabolism. RNA-Seq data suggested that $C$. pertinax switched its metabolism by considerable expression changes in a relatively low number of gene clusters.

Our previous study of $C$. pertinax shows that electrons from $\mathrm{CO}$ oxidation are mainly (62\%) consumed to reduce $\mathrm{H}_{2} \mathrm{O}$ to $\mathrm{H}_{2}$; the remaining electrons are utilized in the reduction of thiosulfate by thiosulfate reductase (cpu_0691006930) (Fukuyama et al. 2018). Genes involved in the transport of ferrous iron (very high category) were largely upregulated under $100 \% \mathrm{~N}_{2}$, suggesting that the ferrous irons were positively transported into cells in heterotrophic growth. Considering that ferrous irons were incorporated as hemes or iron-sulfur clusters in various energy-generating and regulatory proteins (Braun and Hantke 2011), C. pertinax could conserve energy via anaerobic respiration in the modified DSM medium 507 containing sodium thiosulfate. In contrast, in hydrogenogenic $\mathrm{CO}$ metabolism, transport of ferrous iron (very high category) was significantly and incompletely reduced to low expression (Table 1). Instead, both CODH-II gene cluster and ECH gene cluster were largely upregulated. In addition, expressions of the genes encoding thiosulfate reductase were relatively decreased (average read counts were decreased from 3018 to 1843). 
Therefore, owing to the sensitivity of heme protein to $\mathrm{CO}, C$. pertinax would switch from anaerobic respiration to hydrogenogenic $\mathrm{CO}$ metabolism retaining a part of reducing power to the reduction of thiosulfate. The higher yields of $C$. pertinax grew under $100 \% \mathrm{~N}_{2}$ than $100 \% \mathrm{CO}$ (Fig. S1) would be partly explained by a thermodynamic perspective about anaerobic respiration and hydrogenogenic $\mathrm{CO}$ metabolism. In addition, owing to the high sensitivity of CooA-2 to $\mathrm{CO}$ (Techtmann et al. 2011), C. pertinax would switch their metabolisms in response to low $\mathrm{CO}$ concentration.

In general, carboxydotrophs can fix $\mathrm{CO}_{2}$ or $\mathrm{CO}$ to acetylCoA via Wood-Ljungdahl pathway (Ragsdale 2004). In fact, transcriptome analysis of the acetogenic carboxydotroph, Clostridium ljungdahlii, shows that a gene cluster containing most of the genes for Wood-Ljungdahl pathway is significantly upregulated in their CO metabolism (Tan et al. 2013). In our RNA-Seq data, however, expressions of genes in CODH-III-ACS gene cluster were not upregulated regardless of $\mathrm{CO}$ addition. This result suggested that $C$. pertinax could fix carbon via other pathways in response to CO. Actually, a frameshift of CODH catalytic subunit gene in two hydrogenogenic carboxydotrophs suggested that carbon fixation via Wood-Ljungdahl pathway is not essential for hydrogenogenic CO metabolism (Wu et al. 2005; Omae et al. 2017).

In addition to Wood-Ljungdahl pathway, $C$. pertinax is predicted to possess an incomplete TCA cycle and an incomplete 3-hydroxypropionate cycle (Fukuyama et al. 2018). Among the incomplete TCA cycle-related genes, genes for fumarate hydratase (EC: 4.2.1.2; cpu_07820-07830 and cpu_21290-21300) and succinate dehydrogenase (EC: 1.3.5.1; cpu_078240-07850, cpu_15750-15760, and cpu_2126021280) are multicopy (Fukuyama et al. 2017). Of these gene sets, one encoding fumarate hydratase (cpu_0782007830) and succinate dehydrogenase (cpu_07840-07850 and cpu_15750-15760; Table S3) were largely expressed under $100 \%$ CO (very high category), implying that these gene clusters were upregulated in response to $\mathrm{CO}$ and products of these genes enhanced carbon fixation via a part of reductive TCA cycle. Furthermore, $C$. pertinax can conserve energy via their hydrogenogenic $\mathrm{CO}$ metabolism in which $\mathrm{CO}$ oxidation is coupled with $\mathrm{H}_{2}$ production and $\mathrm{CO}_{2}$ is generated as a by-product of this reaction (Yoneda et al. 2012; Fukuyama et al. 2018). Therefore, we hypothesized that, in addition to Wood-Ljungdahl pathway, $C$. pertinax fixed $\mathrm{CO}_{2}$ via reductive incomplete TCA cycle in response to $\mathrm{CO}$.

In bacteria, self-cleaving activity of LexA repressor is stimulated by activated recombinase $\mathrm{A}$ ( $\mathrm{Rec} \mathrm{A})$ during response to DNA damage (SOS response) (Butala et al. 2009). As the temperate prophage also utilizes the bacterial SOS response system, host RecA promotes the entry of lytic phase when SOS response occurs in the host. In the prophage region, a gene encoding transcription repressor LexA (cpu_00820) was expressed under both conditions, whereas other genes such as DNA replication (cpu_00950) and many structure proteins were significantly downregulated under hydrogenogenic CO metabolism condition, suggesting that the lysis of the temperate phage was strictly repressed with $100 \% \mathrm{CO}$. In addition, these data might imply that hydrogenogenic $\mathrm{CO}$ metabolism is more stable than heterotrophic metabolism for $C$. pertinax.

Of the known anaerobic $\mathrm{CO}$-responsive transcriptional factors, two transcriptional factors (CooA and RcoM for carboxydotrophic bacteria) possess heme domain (Kerby et al. 2008) and the other factor (CorQR for carboxydotrophic archaea) possesses 4-vinyl reductase domain to sense CO (Kim et al. 2015). Of the three transcriptional factors as DEGs under $100 \%$ CO, TetR/AcrR family transcriptional factor (cpu_03570) acts as the repressor when it senses cellular environmental dynamics (Deng et al. 2013). On the other hand, LTTRs (cpu_05930 and cpu_07800) is a widespread transcriptional factor in bacteria and acts as either activators or repressors of single or operonic genes (Maddocks and Oyston 2008). However, the LTTRs were not considered to be a CO-responsive transcriptional factor, because these possessed neither heme nor 4-vinyl reductase domains. When we explored transcriptional factor with known CO-sensing domain from $C$. pertinax using BLASTp search, only CooA-2 with heme domain was found. The CooA-binding site was conserved only upstream of the ECH gene cluster, strongly indicating that the $\mathrm{ECH}$ gene cluster was regulated by $\mathrm{CO}$-responsive transcriptional factor CooA regulation. Collectively, it was suggested that only the $\mathrm{ECH}$ gene cluster was regulated by active CooA and others were regulated secondarily in the same transcriptional cascade as the ECH gene cluster. Otherwise, the expression of gene clusters, expect for the ECH gene cluster, was regulated by an undiscovered $\mathrm{CO}$-responsive transcriptional factor.

\section{Conclusion}

Our RNA-Seq analysis showed that $C$. pertinax switched its metabolism through intense expression changes of relatively low number of gene clusters. In heterotrophic metabolism, C. pertinax conserved energy via anaerobic respiration. On the other hand, owing to the inactivation of heme protein by $\mathrm{CO}$, C. pertinax performed hydrogenogenic $\mathrm{CO}$ metabolism under $100 \% \mathrm{CO}$ instead of anaerobic respiration retaining a part of reducing power from $\mathrm{CO}$ oxidation to the reduction of thiosulfate. Notably, genes in the temperate phage were strictly expressed under heterotrophic growth. This result might imply that hydrogenogenic $\mathrm{CO}$ metabolism might be more stable for $C$. pertinax. When $C$. pertinax switches heterotrophic metabolism to $\mathrm{CO}$ metabolism, of the significantly expressed gene clusters under $100 \%$ CO, only the 
ECH gene cluster was regulated by CooA regulation. In addition, no potential CO-responsive transcriptional factors were conserved in $C$. pertinax. These results suggested that only the $\mathrm{ECH}$ gene cluster was regulated by active CooA and others were separately regulated in the same transcriptional cascade as the $\mathrm{ECH}$ gene cluster.

Acknowledgements This work was supported by Grant-in-Aid for Scientific Research (A) (25252038), (A) (16H02569), and (S) (16H06381) from The Ministry of Education, Culture, Sports, Science and Technology (MEXT).

\section{Compliance with ethical standards}

Conflict of interest The authors declare that they have no conflict of interest.

Open Access This article is distributed under the terms of the Creative Commons Attribution 4.0 International License (http://creativeco mmons.org/licenses/by/4.0/), which permits unrestricted use, distribution, and reproduction in any medium, provided you give appropriate credit to the original author(s) and the source, provide a link to the Creative Commons license, and indicate if changes were made.

\section{References}

Altschul SF, Gish W, Miller W et al (1990) Basic local alignment search tool. J Mol Biol 215:403-410. https://doi.org/10.1016/ S0022-2836(05)80360-2

Altschul SF, Madden TL, Schäffer AA et al (1997) Gapped BLAST and PSI-BLAST: a new generation of protein database search programs. Nucl Acids Res 25:3389-3402. https://doi.org/10.1093/ NAR/25.17.3389

Aono S, Nakajima H, Saito K, Okada M (1996) A novel heme protein that acts as a carbon monoxide-dependent transcriptional activator in Rhodospirillum rubrum. Biochem Biophys Res Commun 228:752-756. https://doi.org/10.1006/bbrc.1996.1727

Arndt D, Grant JR, Marcu A et al (2016) PHASTER: a better, faster version of the PHAST phage search tool. Nucl Acids Res 44:W16-W21. https://doi.org/10.1093/nar/gkw387

Bailey TL, Elkan C (1994) Fitting a mixture model by expectation maximization to discover motifs in biopolymers. In: Altman R, Brutlag D, Karp P, Lathrop R and Searls D (eds) Proceedings of the 2nd international conference on intelligent systems for molecular biology. AAAI Press, Menlo Park, pp 226-233

Braun V, Hantke K (2011) Recent insights into iron import by bacteria. Curr Opin Chem Biol 15:328-334. https://doi.org/10.1016/J. CBPA.2011.01.005

Butala M, Žgur-Bertok D, Busby SJW (2009) The bacterial LexA transcriptional repressor. Cell Mol Life Sci 66:82-93. https://doi. org/10.1007/s00018-008-8378-6

Cho S, Kim MS, Jeong Y et al (2017) Genome-wide primary transcriptome analysis of $\mathrm{H}_{2}$-producing archaeon Thermococcus onnurineus NA1. Sci Rep 7:43044. https://doi.org/10.1038/srep43044

Crooks GE, Hon G, Chandonia JM, Brenner SE (2004) WebLogo: a sequence logo generator. Genome Res 14:1188-1190. https://doi. org/10.1101/gr.849004

Deng W, Li C, Xie J (2013) The underling mechanism of bacterial TetR/AcrR family transcriptional repressors. Cell Signal 25:16081613. https://doi.org/10.1016/J.CELLSIG.2013.04.003
Fox J, He Y, Shelver D et al (1996) Characterization of the region encoding the CO-induced hydrogenase of Rhodospirillum rubrum. J Bacteriol 178:6200-6208. https://doi.org/10.1128/ jb.178.21.6200-6208.1996

Fukuyama Y, Omae K, Yoneda Y et al (2017) Draft genome sequences of Carboxydothermus pertinax and C. islandicus, hydrogenogenic carboxydotrophic bacteria. Genome Announc 5:e01648-16. https ://doi.org/10.1128/genomeA.01648-16

Fukuyama Y, Omae K, Yoneda Y et al (2018) Insight into energy conservation via alternative carbon monoxide metabolism in Carboxydothermus pertinax revealed by comparative genome analysis. Appl Environ Microbiol 84:e00458-18. https://doi. org/10.1128/AEM.00458-18

Grahame DA, DeMoll E (1995) Substrate and accessory protein requirements and thermodynamics of acetyl-CoA synthesis and cleavage in Methanosarcina barkeri. Biochemistry 34:4617-4624. https://doi.org/10.1021/BI00014A015

Hammer Ø, Harper DAT, Ryan P (2001) PAST: Paleontological statistics software package for education and data analysis. Palaeontol Electron 4:9

Inoue T, Takao K, Yoshida T et al (2013) Cysteine 295 indirectly affects Ni coordination of carbon monoxide dehydrogenase-II C-cluster. Biochem Biophys Res Commun 441:13-17. https:// doi.org/10.1016/j.bbrc.2013.09.143

Jiang B, Henstra AM, Paulo PL et al (2009) Atypical one-carbon metabolism of an acetogenic and hydrogenogenic Moorella thermoacetica strain. Arch Microbiol 191:123-131. https://doi. org/10.1007/s00203-008-0435-x

Kerby RL, Hong SS, Ensign SA et al (1992) Genetic and physiological characterization of the Rhodospirillum rubrum carbon monoxide dehydrogenase system. J Bacteriol 174:5284-5294. https://doi. org/10.1128/jb.174.16.5284-5294.1992

Kerby RL, Ludden PW, Roberts GP (1997) In vivo nickel insertion into the carbon monoxide dehydrogenase of Rhodospirillum rubrum: molecular and physiological characterization of cooCTJ. J Bacteriol 179:2259-2566. https://doi.org/10.1128/ JB.179.7.2259-2266.1997

Kerby RL, Youn H, Roberts GP (2008) RcoM: a new single-component transcriptional regulator of $\mathrm{CO}$ metabolism in bacteria. J Bacteriol 190:3336-3343. https://doi.org/10.1128/JB.00033-08

Kim MS, Choi AR, Lee SH et al (2015) A novel CO-responsive transcriptional regulator and enhanced $\mathrm{H}_{2}$ production by an engineered Thermococcus onnurineus NA1 strain. Appl Environ Microbiol 81:1708-1714. https://doi.org/10.1128/AEM.03019-14

King GM, Weber CF (2007) Distribution, diversity and ecology of aerobic CO-oxidizing bacteria. Nat Rev Microbiol 5:107-118. https://doi.org/10.1038/nrmicro1595

Kozhevnikova DA, Taranov EA, Lebedinsky AV et al (2016) Hydrogenogenic and sulfidogenic growth of Thermococcus archaea on carbon monoxide and formate. Microbiology 85:400-410. https ://doi.org/10.1134/S0026261716040135

Langmead B, Salzberg SL (2012) Fast gapped-read alignment with Bowtie 2. Nat Methods 9:357-359. https://doi.org/10.1038/nmeth .1923

Lau CKY, Krewulak KD, Vogel HJ (2016) Bacterial ferrous iron transport: the Feo system. FEMS Microbiol Rev 40:273-298. https:// doi.org/10.1093/femsre/fuv049

Leduc J, Thorsteinsson MV, Gaal T, Roberts GP (2001) Mapping CooA. RNA polymerase interactions. Identification of activating regions 2 and 3 in CooA, the co-sensing transcriptional activator. J Biol Chem 276:39968-39973. https://doi.org/10.1074/jbc. M105758200

Liao Y, Smyth GK, Shi W (2014) featureCounts: an efficient general purpose program for assigning sequence reads to genomic features. Bioinformatics 30:923-930. https://doi.org/10.1093/bioin formatics/btt656 
Maddocks SE, Oyston PCF (2008) Structure and function of the LysRtype transcriptional regulator (LTTR) family proteins. Microbiology 154:3609-3623. https://doi.org/10.1099/mic.0.2008/022772-0

Mohr T, Aliyu H, Küchlin R et al (2018) CO-dependent hydrogen production by the facultative anaerobe Parageobacillus thermoglucosidasius. Microb Cell Fact 17:108. https://doi.org/10.1186/ s12934-018-0954-3

Mörsdorf G, Frunzke K, Gadkari D, Meyer O (1992) Microbial growth on carbon monoxide. Biodegradation 3:61-82. https:// doi.org/10.1007/BF00189635

Nishimura Y, Watai H, Honda T, et al (2017a) Environmental viral genomes shed new light on virus-host interactions in the ocean. mSphere 2:e00359-16. https://doi.org/10.1128/msphere.00359-16

Nishimura Y, Yoshida T, Kuronishi M et al (2017b) ViPTree: the viral proteomic tree server. Bioinformatics 106:12826-12831. https:// doi.org/10.1093/bioinformatics/btx157

Oelgeschläger E, Rother M (2008) Carbon monoxide-dependent energy metabolism in anaerobic bacteria and archaea. Arch Microbiol 190:257-269. https://doi.org/10.1007/s00203-008-0382-6

Omae K, Yoneda Y, Fukuyama Y et al (2017) Genomic analysis of Calderihabitans maritimus $\mathrm{KKC1}$, a thermophilic, hydrogenogenic, carboxydotrophic bacterium isolated from marine sediment. Appl Environ Microbiol 83:e00832-17. https://doi.org/10.1128/ AEM.00832-17

Ragsdale SW (2004) Life with carbon monoxide. Crit Rev Biochem Mol Biol 39:165-195. https://doi.org/10.1080/104092304904965 77

Rajeev L, Hillesland KL, Zane GM et al (2012) Deletion of the Desulfovibrio vulgaris carbon monoxide sensor invokes global changes in transcription. J Bacteriol 194:5783-5793. https://doi.org/10.1128/ JB.00749-12

Roberts GP, Youn H, Kerby RL (2004) CO-sensing mechanisms. Microbiol Mol Biol Rev 68:453-473. https://doi.org/10.1128/ MMBR.68.3.453-473.2004

Robinson MD, McCarthy DJ, Smyth GK (2010) edgeR: a Bioconductor package for differential expression analysis of digital gene expression data. Bioinformatics 26:139-140. https://doi. org/10.1093/bioinformatics/btp616

Shelver D, Kerby RL, He Y, Roberts GP (1995) Carbon monoxide-induced activation of gene expression in Rhodospirillum rubrum requires the product of cooA, a member of the cyclic AMP receptor protein family of transcriptional regulators. J Bacteriol 177:2157-2163. https://doi.org/10.1128/ JB.177.8.2157-2163.1995

Shelver D, Kerby RL, He Y, Roberts GP (1997) CooA, a CO-sensing transcription factor from Rhodospirillum rubrum, is a CO-binding heme protein. Proc Natl Acad Sci 94:11216-11220. https:// doi.org/10.1073/pnas.94.21.11216

Soboh B, Linder D, Hedderich R (2002) Purification and catalytic properties of a $\mathrm{CO}$-oxidizing: $\mathrm{H}_{2}$-evolving enzyme complex from Carboxydothermus hydrogenoformans. Eur J Biochem 269:5712-5721. https://doi.org/10.104 6/j.1432-1033.2002.03282.x

Sokolova T, Lebedinsky A (2013) CO-oxidizing anaerobic thermophilic prokaryotes. In: Satyanarayana T, Littlechild JK (eds) Thermophilic microbes in environmental and industrial biotechnology, 2nd edn. Springer, Dordrecht, pp 203-231

Sokolova TG, Henstra AM, Sipma J et al (2009) Diversity and ecophysiological features of thermophilic carboxydotrophic anaerobes. FEMS Microbiol Ecol 68:131-141. https://doi.org/10.11 11/j.1574-6941.2009.00663.x

Solovyev V, Salamov A (2011) Automatic annotation of microbial genomes and metagenomic sequences. In: Li RW (ed) Metagenomics and its applications in agriculture, biomedicine and environmental studies. Nova Science Publishers, Hauppauge, pp $61-78$
Svetlitchnyi V, Peschel C, Acker G, Meyer O (2001) Two membraneassociated $\mathrm{NiFeS}$-carbon monoxide dehydrogenases from the anaerobic carbon-monoxide-utilizing eubacterium Carboxydothermus hydrogenoformans. J Bacteriol 183:5134-5144. https:// doi.org/10.1128/JB.183.17.5134-5144.2001

Tan Y, Liu J, Chen X et al (2013) RNA-seq-based comparative transcriptome analysis of the syngas-utilizing bacterium Clostridium ljungdahlii DSM 13528 grown autotrophically and heterotrophically. Mol BioSyst 9:2775-2784. https://doi.org/10.1039/c3mb7 $0232 \mathrm{~d}$

Tatusov RL (2000) The COG database: a tool for genome-scale analysis of protein functions and evolution. Nucl Acids Res 28:33-36. https://doi.org/10.1093/nar/28.1.33

Techtmann SM, Colman AS, Robb FT (2009) "That which does not kill us only makes us stronger": the role of carbon monoxide in thermophilic microbial consortia. Environ Microbiol 11:1027-1037. https ://doi.org/10.1111/j.1462-2920.2009.01865.x

Techtmann SM, Colman AS, Murphy MB et al (2011) Regulation of multiple carbon monoxide consumption pathways in anaerobic bacteria. Front Microbiol 2:147. https://doi.org/10.3389/fmicb .2011 .00147

Techtmann SM, Lebedinsky AV, Colman AS et al (2012) Evidence for horizontal gene transfer of anaerobic carbon monoxide dehydrogenases. Front Microbiol 3:132. https://doi.org/10.3389/fmicb .2012 .00132

Thorvaldsdottir H, Robinson JT, Mesirov JP (2013) Integrative genomics viewer (IGV): high-performance genomics data visualization and exploration. Brief Bioinform 14:178-192. https://doi.org/10.1093/ bib/bbs01

Trapnell C, Pachter L, Salzberg SL (2009) TopHat: discovering splice junctions with RNA-Seq. Bioinformatics 25:1105-1111. https:// doi.org/10.1093/bioinformatics/btp120

Wawrousek K, Noble S, Korlach J et al (2014) Genome annotation provides insight into carbon monoxide and hydrogen metabolism in Rubrivivax gelatinosus. PLoS One 9:e114551. https://doi. org/10.1371/journal.pone.0114551

Weghoff MC, Müller V (2016) CO metabolism in the thermophilic acetogen Thermoanaerobacter kivui. Appl Environ Microbiol 82:2312-2319. https://doi.org/10.1128/AEM.00122-16

Wösten MM (1998) Eubacterial sigma-factors. FEMS Microbiol Rev 22:127-150. https://doi.org/10.1111/j.1574-6976.1998.tb00364.x

Wu M, Ren Q, Durkin AS et al (2005) Life in hot carbon monoxide: the complete genome sequence of Carboxydothermus hydrogenoformans Z-2901. PLoS Genet 1:e65. https://doi.org/10.1371/journ al.pgen.0010065

Yoneda Y, Yoshida T, Kawaichi S et al (2012) Carboxydothermus pertinax sp. nov., a thermophilic, hydrogenogenic, Fe(III)-reducing, sulfur-reducing carboxydotrophic bacterium from an acidic hot spring. Int J Syst Evol Microbiol 62:1692-1697. https://doi. org/10.1099/ijs.0.031583-0

Yoneda Y, Yoshida T, Daifuku T et al (2013) Quantitative detection of carboxydotrophic bacteria Carboxydothermus in a hot aquatic environment. Fundam Appl Limnol/Arch für Hydrobiol 182:161170. https://doi.org/10.1127/1863-9135/2013/0374

Yoneda Y, Kano SI, Yoshida T et al (2015) Detection of anaerobic carbon monoxide-oxidizing thermophiles in hydrothermal environments. FEMS Microbiol Ecol 91:fiv093. https://doi.org/10.1093/ femsec/fiv093

Youn H, Kerby RL, Conrad M, Roberts GP (2004) Functionally critical elements of CooA-related CO sensors. J Bacteriol 186:1320 1329. https://doi.org/10.1128/JB.186.5.1320-1329.2004

Publisher's Note Springer Nature remains neutral with regard to jurisdictional claims in published maps and institutional affiliations. 